\title{
An online alcohol and risky sex prevention program for college students studying abroad: study protocol for a randomized controlled trial
}

\author{
Eric R. Pedersen ${ }^{1 *} \mathbb{0}$, Elizabeth J. D'Amico ${ }^{1}$, Joseph W. LaBrie ${ }^{2}$, Coreen Farris ${ }^{3}$, David J. Klein ${ }^{1}$ \\ and Beth Ann Griffin ${ }^{4}$
}

\begin{abstract}
Background: This study protocol describes a proposed randomized controlled trial that builds upon a successful pilot intervention study to address problematic and dangerous drinking among young adult college students studying abroad in foreign environments. Despite universities and colleges citing alcohol misuse as the most concerning issue for their students abroad, most institutions offer no empirically-based prevention efforts tailored to this at-risk population. The proposed intervention attempts to fill a major gap for the nearly 333,000 students completing study abroad programs each year by using empirically-based and theoretically-informed risk and protective factors to correct misperceived peer drinking norms and promote cultural engagement abroad. In addition to preventing heavy and problematic drinking, the intervention seeks to prevent risky sexual behaviors (e.g., sex without a condom) and experience of sexual violence victimization, which are strikingly common among study abroad students and have the potential for lasting physical and psychological effects upon return home.
\end{abstract}

Methods/design: We will conduct a randomized controlled trial of an intervention with a sample of 1200 college students studying abroad from approximately 50 US universities and colleges. The brief, online intervention is text and video based and contains evidence-based components of personalized normative feedback to correct students' misperceived drinking norms, content to promote engagement with the cultural experience abroad and address difficulties adjusting to life in the foreign environment, and tips and strategies to prevent risky sexual behaviors and sexual violence victimization abroad. Participants will complete online surveys at five time points (predeparture, first month abroad, last month abroad, 1-month post-return, and 3-months post-return) to assess for intervention effects on drinking behavior, drinking consequences, risky sex, and sexual violence outcomes. We will examine whether the mechanisms targeted by the intervention (changes in perceived norms, engagement in the cultural experience abroad) serve as mediators of intervention efficacy.

Discussion: The proposed study has the potential to fill an important gap in the research literature and provide empirical support for an online accessible, brief, and targeted approach that can easily be distributed to study abroad students to help prevent heavy alcohol use and sexual risk abroad.

Trial registration ClinicalTrials.gov Identifier NCT03928067

Keywords: Alcohol, Sexual violence, Intervention, Online, Study abroad, Young adults

\footnotetext{
${ }^{*}$ Correspondence: ericp@rand.org

${ }^{1}$ RAND Corporation, 1776 Main Street, PO Box 2138, Santa Monica, CA

90407-2138, USA

Full list of author information is available at the end of the article
} 


\section{Background}

The number of young adult students taking advantage of opportunities to study abroad during college is growing. Approximately 1 in 10 American undergraduate college students study abroad before graduating, with nearly 333,000 students completing study abroad experiences in the 2016/2017 academic year [1]. This represents a $120 \%$ increase over the past 15 years. The personal, cultural, and academic benefits of study abroad are many and include increased global perspectives, enhanced selfesteem, preparation for international careers, respect for other cultures, and academic success [2-8].

\section{Study abroad students are at-risk for heavy drinking and negative sexual consequences}

Despite these benefits, American study abroad students represent a large and diverse population at-risk for increased and problematic drinking. Students more than double their weekly alcohol use while abroad and both pre-abroad inexperienced drinkers and the heaviest drinkers abroad return home drinking at higher levels than before they left [9-11]. A substantial portion of students face negative alcohol-related consequences while abroad [9, 10]. For example, in one study, more than one-third of study abroad students reported taking risks or doing impulsive things while drinking they later regretted [9], and in another study, at least 1 in 10 students reported drinking to the point of passing out or blacking out, missing classes, finding themselves in dangerous situations, or experiencing alcohol-related injuries [10]. The novelty of the abroad context creates a wider range of abroad-specific consequences than are present on campus (e.g., offending host families, losing passports, disrupted travel plans) [9]. In addition, consequences may be exacerbated abroad or develop into long-term problems due to limited access to resources and familiar coping strategies (e.g., being far from friends/family; being unfamiliar with local healthcare locations or law enforcement policies). University administrators and personnel working with study abroad students also report substantial concerns with their students' drinking behavior abroad [12-15].

In addition to heavy drinking, students are also exposed to a number of sexual risks while abroad, including risky sexual behaviors (e.g., unprotected sex with multiple partners) and sexual violence (ranging from non-consensual sexual contact to attempted and completed sexual assault by force) [16]; many of these risks are amplified by heavy drinking. A well-established line of research with college students on campus indicates that heavy alcohol use increases risky sexual behavior, and is associated with increased risk for sexual assault victimization and perpetration among both male and female students
[17-20]. Increases in heavy drinking within a novel environment alone may place students at risk for sexual violence victimization. Back on campus, at least half of sexual violence incidents on campus involve victim and/ or perpetrator drinking; most often both are intoxicated $[19,21]$. Heavy drinkers are most at-risk, but even light or non-drinkers that engage in heavy drinking during a particular situation (such as during an abroad trip) are at increased sexual risk [22]. Thus, the nature of heavy drinking abroad, coupled with unique risks found in the abroad environment, likely contribute to greater sexual risk abroad.

The literature on sexual risk abroad is only emerging, however, small cross sectional studies from single universities have shown that between 25 and $50 \%$ of male and female students report risky sexual behavior [9, 23, 24], upwards of $75 \%$ of female students report some form of sexual victimization while abroad [23-26], and female students are at three times higher risk for attempted sexual assault and five times higher risk for completed sexual assault abroad compared to their risk back home on campus [25], where rates are already high (upwards of 1 in 5 female students) [27]. Men are also not immune to sexual victimization abroad; in one study nearly 1 in 10 reported pressure to have sex with someone while intoxicated [9]. These events can ruin study abroad experiences and lead to lasting physical and psychological effects (e.g., sexually transmitted infections, pregnancy, trauma).

\section{The need for evidence-based prevention programs specific to study abroad risk}

A review of study abroad drinking revealed that while there is ample evidence showing that drinking in study abroad contexts is more problematic than domestic oncampus drinking, there has been little attention or targeted interventions aimed at this high-risk environment [28]. In addition, content analysis of 753 US study abroad program websites revealed that institutions provide limited information about alcohol use and sexual risk on their websites [29]. Furthermore, although study abroad program directors report that they discuss alcohol and associated sexual risks with their students prior to abroad [30], the majority of students report that they do not receive any predeparture alcohol or sexual risk programming [31]. Thus, a program designed to target this large at-risk group and the unique risk factors faced abroad has the potential to fill an important gap and produce widespread and lasting physical and/or psychological benefits. Though most college campuses provide all students alcohol programs and sexual violence prevention programs, the nature and extent of heavy drinking, risky sex, and sexual victimization abroad are very different than on campus, and programs geared toward all students (and 
in particular, those on campus) may not target the specific risks experienced by students when the go abroad. Increased drinking rates combined with unfamiliar surroundings, impaired judgment around the prudence of certain behaviors in the novel cultural environment, and limited comprehension of the nuances of local culture may increase the potential for negative alcohol and sexual outcomes. Thus, there is a need for prevention programs specifically targeted toward study abroad students and their unique risks in the novel environment.

\section{Risk and protective factors for study abroad students Normative drinking misperceptions}

Incorrect perceptions of drinking abroad are a major factor contributing to increased and problematic drinking while studying abroad. Within the study abroad environment, perceived norms of study abroad peers are robustly associated with heavy drinking abroad and predict increases in drinking behavior from predeparture to during the abroad experience $[9,32,33]$. In addition to perceptions of other US student peer drinking while abroad, perceptions of the normative drinking of native young adults in one's host country are uniquely associated with student drinking [32], such that if a student believes local people are heavier drinkers, he or she is, in turn, likely to drink more heavily as well. This is true even when controlling for per capita alcohol consumption in the students' host countries [32], suggesting that perceptions of what local people are doing are more influential on personal drinking than the actual drinking levels of the host country.

Targeting misperceptions of peer alcohol use through personalized normative feedback (PNF) interventions can correct misperceptions and prevent heavy drinking during high-risk events. Correcting misperceptions of peer drinking norms through PNF has become one of the most prominent strategies for addressing excessive alcohol use among college students [34-38]. Interventions based solely on PNF have demonstrated small to large effect sizes [39-41], with changes in perceptions of peer behavior mediating intervention effects [42-45]. Even in interventions that include several components in addition to PNF, the effects are generally mediated by augmented normative perceptions rather than variables associated with the other components typical to brief interventions (e.g., weighing pros and cons of changing behavior) [46-48]. Most of this research has focused on reducing pre-existing drinking patterns; however, in recent work, PNF interventions have been adapted to proactively prevent drinking during specific future events known to represent heightened risk, such as 21st birthday and spring break trips [41, 49-51].
In our pilot work with a sample of 343 study abroad students from one university, we found that providing PNF focused on salient and proximal reference groups (i.e., study abroad peers; country-specific young adults native to one's host country) prior to their departure helped students form more accurate beliefs about drinking within their host country and prevented escalation of drinking while abroad [52]. However, we also found that heavier drinking students that received PNF alone failed to report significantly less drinking during abroad than those heavy drinkers not receiving PNF. This may be because students expect to drink more while abroad and believe alcohol will be a central part of their abroad experience [9]. Helping students navigate this unique environment could reduce risk and consequences. In addition, a key aspect of PNF is that, after learning the actual norms for their environment, participants confirm the veracity of these new norms themselves by observing the behavior of peers and local people post intervention. However, this critical norm confirmation step is missed among students abroad who spend little time engaging their new cultural environment (e.g., spending most of one's time socializing with other American students) because such students avoid the local sociocultural environment where these cross-cultural drinking norms would be visible. Thus, study abroad students may require an additional innovative approach that not only addresses the perceived norms that can contribute to increased drinking while abroad, but also addresses the importance of understanding one's host country and the study abroad context. Doing so can help students navigate this new environment more successfully and therefore be less likely to drink heavily.

\section{Sojourner adjustment}

Poor adjustment into the foreign environment and limited engagement with the local culture represent additional risk factors for heavy drinking while abroad. Theories of acculturation [53, 54] and, more specifically, sojourner adjustment (i.e., the sociocultural and psychological adjustment of relatively short-term visitors to new cultures) [55] posit that immigrants and students who attempt to integrate or assimilate more fully into their new culture are at the least risk for sociocultural and psychological adjustment difficulties [53, 54, 56-60]. Research and theory also suggest that if young people transition to a temporary novel risky environment (e.g., spring break, Mardi Gras in New Orleans) and they do not feel connected to their environment, they may view their time as a temporary reprieve from real life (i.e., a "backspace"), transgress drinking and sexual norms, act in ways inconsistent with their personalities, and, thus, 
be more likely to engage in risky behaviors such as heavy drinking and risky sex [61-64].

Our research with American study abroad students suggests that those most at-risk for heavy drinking and consequences are those who separate themselves from the host environment (i.e., placing more emphasis on the home/US culture), those who perceive the abroad culture as very different than their home culture, those who spend more time with other Americans while abroad, those who feel out of place being away from home, and those who experience anxiety about interacting in the foreign environment $[9,32]$. Other work has confirmed that this negative sojourner adjustment is associated with greater risk for heavy drinking and problems abroad $[65,66]$. Conversely, we have also found that positive sojourner adjustment (i.e., quality/quantity of time with local people, active engagement with cultural experiences and events, foreign language development/use, identification as a member of the host culture) protects students from heavy alcohol use and problems [10]. Thus, promoting cultural engagement and helping with adjustment/ transition to life in a foreign environment may prevent incidences of problematic drinking abroad [2, 67-69]. Positive sojourner adjustment can relate to taking advantage of cultural learning experiences by participating in local customs and spending time with local people, rather than focusing on drinking-centered social experiences with other American students. Culturally-engaging activities may also serve as healthy alternatives and provide a means of achieving social and recreational goals without drinking [70], potentially reducing motivation to drink for both social and coping reasons and, therefore, reducing alcohol use and consequences while abroad. Importantly, preventing heavy drinking patterns from forming abroad may also prevent continued heavy drinking once students return home.

\section{Targeting both normative drinking misperceptions and sojourner adjustment}

Our work has shown that study abroad students who greatly overestimated drinking behavior and who reported negative sojourner adjustment had the highest risk of drinking and consequences [32]. It was also evident from our pilot study that providing PNF alone, which works well for students back on campus, was not a sufficient stand-alone intervention for study abroad students-an established heavy drinking group at risk for multiple negative consequences. Misperceived norms back on campus are based on years of observation of peers (Social Learning Theory [71]; e.g., noticing the few heavy drinkers at a party and falsely believing these heavy drinkers are the majority) and the perpetuation of college heavy drinking stereotypes (e.g., movies such as Animal
House and Old School; discussions with friends about the parties that occurred). Yet study abroad students are entering a new environment with little to no context to make predictions about what drinking norms may look like in the foreign country (both by their study abroad peers and by local young adults). The promotion of cultural engagement in addition to PNF can help students better understand ways to engage in this new environment without the exclusive company of their American peers, affording valuable opportunities to observe that their perceptions of drinking may have been inaccurate. Our pilot work showed that students provided with sojourner adjustment feedback (SAF) in addition to PNF prior to departure abroad experienced significantly fewer alcohol-related consequences abroad compared to students in a control condition, with the greatest benefits for the most at-risk students-those reporting heavier consequences at predeparture [52].

\section{Other risk factors}

Risk factors inherent to the abroad environment are also present and will likely impact any intervention effects on programming seeking to prevent heavy drinking and problems abroad. Many students may be going abroad before they turn 21 years old, which is the legal age to purchase and consume alcohol in the United States, but in nearly all countries that students travel to, the drinking age is lower. Thus, students may be studying abroad in cultures where it is now legal for them to access alcohol and research shows that those under 21 are at greater risk for increased drinking abroad [11, 72]. Moreover, where students choose to travel is associated with their drinking behaviors, with students studying in European countries and Australia drinking more heavily than students studying in other countries. Gender is also important as longitudinal studies show increases in drinking for both genders but greater drinking abroad for men [11, 72]. Furthermore, those with more socially motived reasons for drinking and those who may be drinking to cope (e.g., to alleviate feelings of homesickness or feeling out of place) tend to drink at greater levels abroad [10, 65], and those students who believe alcohol will play a large role in their study abroad experience report more alcohol-related consequences while abroad [9].

\section{The present study}

Expanding on our promising pilot findings, we designed the present study to refine and further test the PNF + SAF intervention in five specific ways with a large sample of students across multiple diverse colleges and universities in the US. First, discussions with users of the pilot program indicated that the text-heavy feedback presented was too broad and difficult to absorb. Thus, we will 
update the normative content to reflect drinking in one's specific country of study and make the SAF more interactive, including video testimonials from study abroad students discussing engaging in the culture and staying safe abroad. Second, given emerging research highlighting increased risk for study abroad alcohol-related risky sexual behavior and sexual victimization [24-26], we will include content on preventing sexual risk and evaluate sexual risk outcomes. Third, we will expand on the small pilot study to test the refined brief, online preventive approach with a proposed 1200 students on a large scale across multiple universities and colleges (i.e., 50+ institutions that have expressed interest in helping us with recruitment of their students). Fourth, we will examine effects on heavy drinking and consequences during both the high-risk event as well as when students return, as these students are at risk for increased drinking postreturn compared to their non-study abroad peers $[10,66$, 73]. Finally, we will test mediators of changes in perceived norms and reports of sojourner adjustment abroad (the mechanisms targeted in the intervention) and moderators of intervention efficacy known to be associated with problematic use abroad. Mainly, we will test whether younger students (i.e., those under age 21), men, those studying in Europe, those who drink for social and coping reasons abroad, those with expectancies that alcohol will play a large role in their experience while abroad, and baseline heavier drinkers will benefit most from the PNF + SAF intervention [9-11, 52, 65, 72]. We will also examine history of sexual violence prior to abroad as a moderator of intervention effects on sexual violence outcomes, given prior work documenting that sexual violence history moderates outcomes in online-delivered alcohol and sexual violence programming $[74,75]$.

\section{Methods/design \\ Overview}

The present study will occur in two phases. Phase 1 will involve a large-scale documentation of the drinking patterns of a proposed 2500 students studying abroad and the video collection of testimonials/advice from a proposed 20 students who have previously studied abroad. Normative drinking content and video footage from study abroad students will be used to develop the intervention. In Phase 2, we will conduct a parallel group randomized controlled trial (RCT), where we will test the enhanced intervention among a different sample of 1200 students from approximately 50 US institutions. We will test the efficacy of the intervention on preventing problematic drinking behavior, risky sexual behaviors, and experiences of sexual violence in this high-risk environment during the first and last month abroad and on sustained effects once students return to campus at 1 - month and 3- months post-return.
The hypotheses are that those student participants who receive the intervention will drink less, experience fewer alcohol-related consequences, engage in fewer risky sexual behaviors, and experience lower rates of sexual violence abroad and back home on campus compared to student participants in a control group.

\section{Participants}

Students will be deemed eligible to participate if they (1) are between the ages of 18 and 24, (2) are signed up to study abroad in one of the 12 most popular destinations (i.e., United Kingdom, Italy, Spain, France, Germany, China, Ireland, Australia, Costa Rica, Japan, South Africa, and Mexico; representing $60 \%$ of study abroad students [1]), and (3) plan to study abroad for between 8 and 20 weeks (approximately one quarter/semester), which represents about two-thirds of all student abroad students [1].

\section{Procedures}

Representatives from the study abroad offices at the 50 institutions will email prospective students to inform them about the study. Interested students will fill out an online sign-up sheet to assess eligibility. We will then randomly invite students into the study to ensure we have adequate numbers of both male and female genders represented. Invited students can consent to participate in the study and fill out measures collected online. Participants' confidential data will be tracked by PIN codes. Participants will read an electronic IRB consent form and indicate consent before enrolling in the study. We will recruit 1200 participants who will be randomly assigned to the intervention condition $(\mathrm{N}=600)$ or a control condition $(\mathrm{N}=600)$. Intervention participants will receive the 30 to $40 \mathrm{~min}$ intervention as described below. Control participants will receive a link to a general website offering study abroad advice and will be asked to spend at least 30 to $40 \mathrm{~min}$ reviewing their institution's study abroad website content, including policies for drinking abroad. This control condition was selected as a form of "treatment as usual" as our conversations with study abroad personnel indicated this is the extent of typical information students receive about alcohol use abroad. Many students also attend predeparture informational orientation sessions where alcohol use and sexual risk may or may not be briefly discussed; we will control for receipt of orientation sessions that cover such topics in analyses.

Participants will complete a survey approximately 2 weeks prior to departure, one survey during their first month abroad, one during their last month abroad, one during their first month back in the US, and a final follow up 3 months post-return to the US. The last survey 
completed abroad represents the final 30 days of the trip, which, for the majority of students in the study, will be the third month abroad. Length of program will be controlled for in analyses. Participants will receive a \$20 Amazon gift card for each of these 15 to 20 min surveys that they complete. Email, text, and phone call reminders will assist with reducing attrition on surveys, which helped us retain $80 \%$ of participants in our pilot work and other RCTs [52, 76]. A diagram of participant flow through the intervention study is found in Fig. 1. Figure 2 contains a SPIRIT (Standard Protocol Items: Recommendations for Interventional Trials) flow diagram of the RCT schedule of enrollment, interventions, and assessments.

\section{Phase 1 documentation of drinking norms and student testimonials}

In the first phase of this project, we collected normative drinking data from 2650 study abroad students from 65 universities and colleges. Normative drinking by gender and by country will be presented in the intervention. Based on our prior work, we expected norms to be generally moderate and they will be displayed in a manner that documents that the majority of students abroad drink moderately rather than heavily. The PNF serves to correct misperceived norms and participants see that their intended drinking at predeparture, as well as their perceptions of peer drinking,

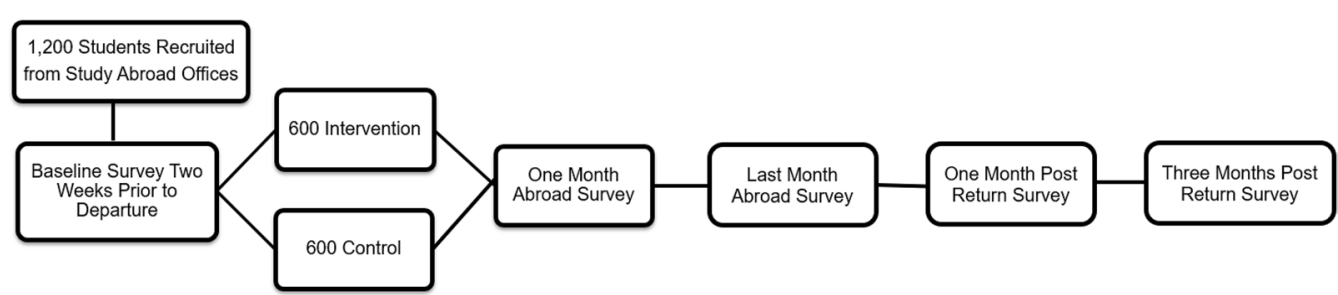

Fig. 1 Phase 2 randomized controlled trial study flow

\begin{tabular}{|c|c|c|c|c|c|c|c|c|}
\hline \multirow[b]{3}{*}{ TIMEPOINT } & \multicolumn{8}{|c|}{ STUDY PERIOD } \\
\hline & \multirow{2}{*}{$\begin{array}{c}\text { Enrollment } \\
t_{1}\end{array}$} & \multirow{2}{*}{$\begin{array}{c}\text { Allocation } \\
0\end{array}$} & \multicolumn{5}{|c|}{ Post-allocation } & \multirow{2}{*}{$\begin{array}{c}\text { Close-out } \\
t_{6}\end{array}$} \\
\hline & & & $\begin{array}{c}t_{1} \\
\text { Predeparture }\end{array}$ & $\begin{array}{c}t_{2} \\
\text { First month } \\
\text { abroad }\end{array}$ & $\begin{array}{c}t_{3} \\
\text { Last month } \\
\text { abroad }\end{array}$ & $\begin{array}{c}\boldsymbol{t}_{4} \\
\text { One-month } \\
\text { post-return }\end{array}$ & $\begin{array}{c}t_{5} \\
\text { Three-months } \\
\text { post-return }\end{array}$ & \\
\hline \multicolumn{9}{|l|}{ ENROLLMENT: } \\
\hline Eligibility screen & $\mathrm{x}$ & & & & & & & \\
\hline Informed consent & $\mathrm{x}$ & & & & & & & \\
\hline Randomization & $x$ & & & & & & & \\
\hline Allocation & & $\mathrm{x}$ & & & & & & \\
\hline \multicolumn{9}{|l|}{ INTERVENTIONS: } \\
\hline \multicolumn{9}{|l|}{$P N F+S A F$} \\
\hline \multicolumn{9}{|l|}{ Control } \\
\hline \multicolumn{9}{|l|}{ ASSESSMENTS: } \\
\hline Heavy drinking and & & & $x$ & $x$ & $x$ & $x$ & $x$ & \\
\hline Risky sexual behavior & & & $\mathrm{x}$ & $x$ & $x$ & $\mathrm{x}$ & $\mathrm{x}$ & \\
\hline $\begin{array}{c}\text { Sexual violence } \\
\text { victimization }\end{array}$ & & & $\mathrm{x}$ & & $\mathrm{x}$ & & $\mathrm{x}$. & \\
\hline
\end{tabular}

Fig. 2 SPIRIT flow diagram of the RCT schedule of enrollment, interventions, and assessments 
may be more than the actual drinking of their peers abroad. In addition, we proposed to interview study abroad students about their experiences with drinking (both by peers and by local people) and experiences with sojourner adjustment abroad. Selected clips from these interviews will be loaded into the intervention template so RCT student participants can hear about moderate drinking abroad, such as how local people view alcohol as a complement to a meal rather than as a means to get intoxicated, and how peers that spent most of their time in bars with other Americans risk missing out on meaningful social and cultural experiences.

Video clips will also display students discussing ways in which they engaged with the culture while abroad, with content focused on facets of sojourner adjustment [77]. For example, clips will show students discussing tips and strategies for how they started conversations with local people, how they found out about local cultural events, what they did to help themselves feel more like a local person rather than a tourist, and how they overcame anxiety about using the local language and strengthened their cultural experience by practicing with local people. Negative sojourner adjustment will also be addressed, with clips of students discussing how they expanded beyond their American student network while abroad and how they managed feelings of homesickness and "culture shock" while abroad. Lastly, video clips will feature students describing ways in which they stayed safe while abroad, with an emphasis on prevention of sexual violence victimization abroad. Students will discuss avoiding unwanted sexual experiences, tips for protecting oneself if choosing to have a sexual relationship abroad, and seeking help if one does experience any sexual violence abroad.

\section{Phase 2 RCT}

A sample of 1200 eligible students will be randomly assigned via computer-generated random numbers to complete the intervention $(\mathrm{N}=600)$ or control $(\mathrm{N}=600)$. Participants will be randomly selected from the interested students for inclusion and randomized to the intervention or control conditions in a stratified fashion to ensure equal cells by gender (male, female), age $(21+$ and under 21$)$, host country (European vs. non-European), and institution type (small college vs. large university). If randomized to the intervention condition, participants will immediately receive the intervention after completing the predeparture survey. Participants can view their feedback again if they desire and will be resent a link to their feedback via email during their first and last month abroad.

\section{PNF component}

During the initial part of the intervention, participants will be asked to indicate how many drinks on average they think they will drink on a typical drinking day while abroad, as well as how many days in a typical month while abroad they will drink 5 or more for males/4 or more for females on an occasion (heavy drinking days). On-screen PNF will be presented containing information on the drinking behavior and attitudes about their gender- and country-specific study abroad peers in graphical and text format. As is standard in PNF interventions [78], a graph will display the participant's intended drinking, their perception of the drinking of their gender- and country-specific peers, and the actual norm we have collected in Phase 1 (see example in Fig. 3). Text will also display moderate drinking norms (e.g., males students in China report drinking about 3 drinks per occasion"). This PNF format has been used in our prior work and with other event-specific prevention interventions targeting intended drinking behavior prior to high-risk events such as 21 st birthday and spring break trips $[41,49,50]$. Participants will then watch video clips of students discussing that drinking among both peers and local people was moderate and less than they had expected before they went abroad.

\section{SAF component}

The SAF-focused content of the intervention will be similar to what we used in our pilot work [52], which was developed through a thorough review of the literature on sojourner adjustment [55, 60, 77] and focus groups with students to generate tips and strategies for meeting goals of sojourner adjustment abroad. As noted above,

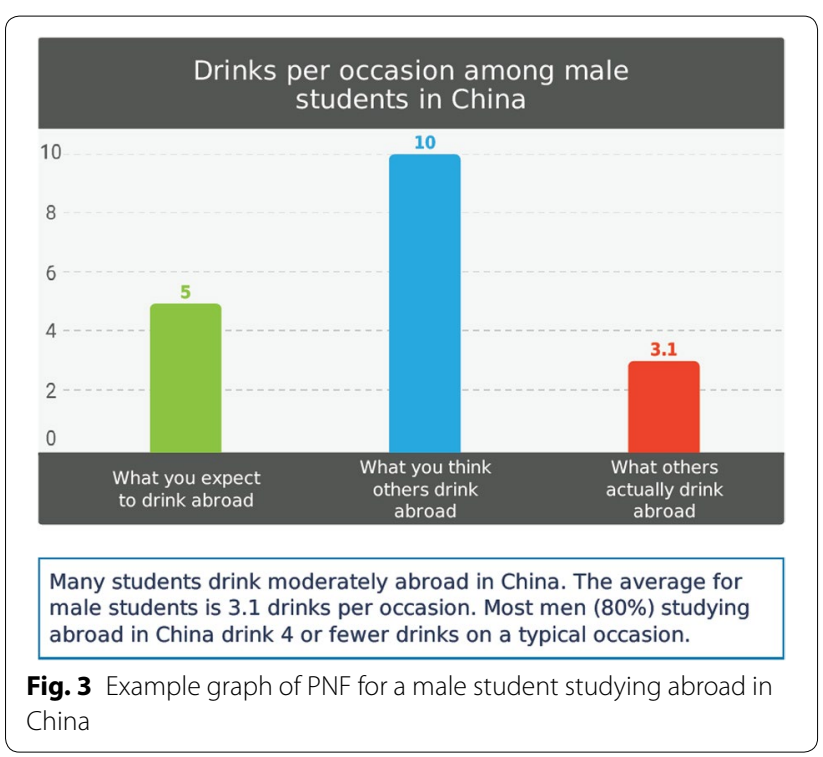


we will enhance the SAF by making it more interactive through the use of video testimonials [77]. Participants will view text-based tips and strategies and watch clips of students discussing how they engaged with the culture while abroad. All content focuses around the four aspects of positive sojourner adjustment (social interaction with host nationals, cultural understanding and participation, language development and use, host culture identification) and the two negative sojourner adjustment factors while abroad (i.e., social interaction with co-nationals [(i.e., other Americans], homesickness/feeling out of place) [77]. These video testimonials were collected from eight students that had recently returned from study abroad experiences in several different countries. Students were selected based on diversity of race/ethnicity, gender, and location of study abroad. They were interviewed on campus using a structured interview based on the facets of sojourner adjustment [77]. Clips from these interviews were vetted with study abroad experts and selected based on sufficient coverage of the cultural engagement issues students may encounter while abroad.

\section{Staying safe component}

Based on review evidence-based approaches for sexual violence prevention back on campus [74, 75], we will include components to address safety behaviors while abroad in three areas: avoiding unwanted sexual experiences abroad, having a safe sexual relationship abroad, and seeking help if one experiences sexual violence or a negative sexual consequence abroad (e.g., contracting a sexually transmitted disease). The intervention will contain text-based tips and protective strategies to be used abroad to reduce sexual risk and sexual violence victimization, as well as clips of students discussing these tips and strategies and encouraging help seeking if one should experience sexual violence abroad. Strategies include having a plan to get out of a potentially unsafe situation, using protection if choosing to engage in sexual activity, ensuring that consent is received during sexual experiences, and looking out for friends and stepping in if they appear to be in a dangerous situation (bystander intervention). Video clips of students discussing methods they used to stay safe abroad will be included. All included content was vetted with research and clinical experts in sexual violence.

\section{Analytic plan}

\section{Main effects of the PNF intervention}

We will analyze five outcomes (total drinks per week, number of heavy drinking days, alcohol-related consequences, risky sex behaviors, and experience of any sexual violence victimization) within a multilevel modeling framework, with the level 1 units being measurement occasions, the level 2 units being individuals, and the level 3 units being schools. Our models will include random effects for the individual students as well as schools to properly adjust for correlations among the repeated measures within an individual student and the students attending the same US school. By analyzing within a multilevel framework, we can investigate whether the intervention is differentially effective at different time points. The main analysis is to estimate the effect of the intervention compared to control at each follow-up time (the first and last month abroad and 1- and 3- months post-return). The $\mathrm{N}$ of 1200 was determined in a priori power analyses to be sufficient to detect small to moderate intervention effect sizes for all primary outcomes.

\section{Outcome measures}

Primary outcomes of the intervention are prevention of heavy and problematic drinking abroad, prevention of risky sexual behaviors abroad, and prevention of any sexual violence victimization abroad. Any observed intervention effects seen during abroad on the first and last month abroad surveys are anticipated to sustain through the first- and third-month post-return to the US, such that intervention participants will drink less, experience fewer problems, engage in fewer risky sexual behaviors, and experience fewer sexual violence events than control participants in the 3 months following return from abroad.

Heavy drinking and alcohol-related consequences Three prespecified drinking outcomes are total drinks per week, number of heavy drinking occasions, and number of alcohol-related consequences in the past 30 days. Drinking in the past 30 days will be assessed at all time points with the Daily Drinking Questionnaire (DDQ; [79]), which asks participants about their typical drinking on each day of a typical week in the past month. It will be used to generate the main drinking outcome of drinks per week but will also yield drinking variable we will look at descriptively (typical drinks consumed per occasion, drinking days per week). A single item will also assess frequency of heavy drinking ( $5+$ drinks on one occasion for males; $4+$ drinks on one occasion for females; known in some studies as "binge drinking"). Consequences from alcohol use in the past month will be assessed on all surveys with the 24-item Brief Young Adult Alcohol Consequences Questionnaire (B-YAACQ), a measure of negative consequences often used with the college population [80, 81]. The scale assesses alcohol-related consequences experienced in the past month (yes/no) with a sum score from 0 to 24 . 
Risky sex Risky sex (e.g., number of partners, use of condoms) in the past month will be assessed with the Sexual Risk Survey (SRS), a 23-item measure designed and validated with college student samples [82]. The SRS will be modified to assess past month behavior as opposed to past 6-month behavior so we can assess this outcome during equal time periods across surveys. The SRS allows for open-ended responses that are then recoded into ordinal categories for generating an overall score, as well as five composite scores of sexual risk taking with uncommitted partners, risky sex acts, impulsive sexual behaviors, intent to engage in risky sexual behavior, and risky anal sex acts [83]. A composite SRS score will be used in analyses as the risky sex outcome, with specific subscale scores examined descriptively.

Sexual violence victimization Sexual violence victimization will be assessed primarily with the Sexual Experiences Survey (SES) [84-86], validated with college students and used in prior work with study abroad students $[16,17$, 25]. The measure will be modified and informed by items from the National Drug-Facilitated, Incapacitated, and Forcible Rape study [87] to include 12 gender- and sexspecific items that reflect five aspects of sexual violence victimization: non-consensual/unwanted sexual contact, sexual coercion, completed sexual assault by force, alcohol- and drug-facilitated sexual assaults, and attempted sexual assault, as well as a composite score of any type of sexual violence victimization. The specific items and gender- and sex-specific wording are included in the Appendix. Response options at predeparture capture whether any sexual violence victimization was experienced prior to going abroad (both in college and prior to college). Participants will fill out the measure again during the last month abroad survey to reflect experience of any sexual violence victimization during the entire trip abroad. Finally, participants will complete the measure again during the 3-month post-return surveys to reflect whether they have experienced any sexual violence victimization since returning to the US from study abroad. Experience of any sexual violence abroad will be the main outcome for sexual violence victimization, but we will decribe the categories of non-consensual/unwanted sexual contact, sexual coercion, completed sexual assault by force, alcohol- and drug-facilitated sexual assaults, and attempted sexual assault descriptively.

\section{Mediator and moderator effects on the intervention}

We will investigate the mechanisms of effects through mediation (changes in perceived norms; experience with sojourner adjustment). Mediation will be investigated within the multilevel modeling framework, using bootstrapping to investigate the standard errors (and hence statistical significance) of mediated effects [88-91]. Second, we will investigate potential moderators (age, gender, host country, institution type, race/ethnicity, baseline drinking, drinking motives while abroad, predeparture expectancies, history of sexual violence) of the association between the intervention and main outcomes by incorporating multiplicative interaction terms into the model described above. Given the high number of candidate moderators in our analyses, we will adjust for multiple testing concerns in our moderation analyses by using a Benjamini-Hochberg adjustment to the $p$-value.

\section{Measures of mediators}

The intervention has two major components (PNF and $\mathrm{SAF}$ ), and we have included measures to assess whether changes in perceptions and engagement in positive sojourner adjustment mediate observed effects of the intervention.

Perceptions Using a modified Drinking Norms Rating Form (DNRF) [92] participants will be asked about perceived drinking of a typical gender-specific study abroad student in their host country and of a typical native in their host country (i.e. someone born in the country and living there currently). The DNRF is modeled after the DDQ to assess perceptions for each reference group regarding perceived total drinks per week, perceived drinking days, and perceived average drinks during a typical month during the same time period the participants is studying abroad. Perceived number of heavy drinking days per month will also be assessed. Changes in these perceptions (average drinks per occasion, heavy drinking days) are hypothesized to serve as mediators of the intervention as these two perceptions will be directly targeted in the PNF.

Sojourner adjustment We will use the 24-item Sojourner Adjustment Measure (SAM; [77]) to assess the four positive and two negative sojourner adjustment factors. This scale contains a 7 -point Likert scale $(1=$ disagree strongly to $7=$ agree strongly) to assess engagement in the four factors of positive sojourner adjustment and two negative sojourner adjustment factors. The SAM will assess actual experience of the six factors abroad to examine changes in sojourner adjustment over time as a mediator of intervention effects. Each of the six factors will be included separately in analyses: the four positive factors of social interaction with host nationals, cultural understanding and participation, language development and use, host culture identification; the two negative factors of social interaction with co-nationals and homesickness/feeling out of place. The SAM factors have demonstrated adequate reliability and convergent validity with established measures of acculturation [77]. 


\section{Measures of moderators}

Based on prior work and pilot study findings, we hypothesize that younger students (i.e., those under age 21), men, those studying in Europe, those who drink for social and coping reasons abroad, those with expectancies that alcohol will play a large role in their experience while abroad, and baseline heavier drinkers will benefit most from the PNF + SAF intervention [9, 11, 52, 72]. Items on the predeparture survey will assess age, gender, and location of study. Drinking motives will be assessed in the two abroad assessments with two subscales from the 20-item Drinking Motives Questionnaire-Revised [93] regarding coping and social motives (5 items each). This measure has displayed adequate reliability in general student and study abroad student samples [10, 94, 95]. Expectancies about the role alcohol will play in the study abroad experience will be assessed at predeparture with a measure we have used in our study abroad work ( $\alpha=0.84$ in prior work) [9]. Participants will rate their agreement with 13 statements (e.g., "I will drink alcohol more often abroad than I drink now," "alcohol will make my study abroad experience more fun") from 0 (strongly disagree) to 4 (strongly agree). Baseline heavy drinking will be defined as a continuous value for total drinks per week from the DDQ. History of sexual violence will be defined as any experience of sexual violence prior to abroad (either in college or prior to college). Institution type (small college/university vs large university) and student race/ethnicity will also be accessed and be examined as additional exploratory moderators.

\section{Discussion}

\section{Limitations and alternative methods considered}

We have considered alternative methodological approaches and attempted to address limitations to this study protocol. First, the use of longitudinal self-report measures collected via the Internet could be associated with attrition and bias. However, research suggests confidential surveys enhance reliability and that validity and response rates are higher for web than mailed surveys [96-99]. In addition, we achieved retention rates of $80 \%$ or better in the pilot study with multiple assessments while abroad [52].

Second, we considered potential iatrogenic effects from the PNF, but note that studies with college students have suggested that iatrogenic effects are rare in PNF interventions [40, 41]. Light drinkers and non-drinkers who receive PNF report less drinking and more sustained abstinence compared to non-PNF control participants [100]. The manner in which we frame our norms presentation also minimizes iatrogenic effects. For example, it may be accurate to state "only 1 in 10 students studying in Ireland abstained during their trip," yet this message conveys that abstaining is actually atypical and only a few students do it. Instead, we would combine this information with moderate drinkers and frame the message as " $80 \%$ of students studying in Ireland report drinking less than 3 drinks on a typical night," which conveys that moderate drinking is typical. This is how we framed normative drinking messages in our pilot work [52].

Third, we chose three primary drinking outcomes because it allows us to see nuanced heavy and problematic behavior. Frequency may increase as a function of the culture abroad (e.g., wine with dinner) and may not be particularly problematic; thus heavy drinking in the form of total weekly quantity and frequency (total weekly drinks) and heavy drinking (i.e., drinking enough to be intoxicated; binge drinking), as well as number of consequences, are our outcomes of interest. We also focus on 12 locations to allow us to personalize the content. These common host countries are skewed European; however, these sites represent $60 \%$ of all students abroad [1] and we do include representation of the most popular Asian and Latin American host countries. If the approach is successful, country-specific content for the less popular sites abroad can be developed.

Lastly, we primarily focus on sexual assault victimization and not perpetration as we will likely be underpowered to report any meaningful effects on the low base rate of admitted perpetration in the sample. Both men and women report sexual risk abroad [9] and we include gender as a moderator in outcome analyses.

\section{Conclusion}

In sum, the proposed RCT innovatively extends normative feedback interventions by examining a tailored PNF-adapted intervention that uses additional content regarding SAF to reduce alcohol and sexual risk in young adults studying abroad-a significant and understudied high-risk group entering into a risky foreign context. Although study abroad and student affairs personnel recognize drinking abroad and sexual risk as major concerns and desire empirically-based programs for students as they enter a known period of risk, there currently are few targeted resources for this population. If the proposed intervention is efficacious, as hypothesized, it can be widely implemented at institutions across the country to help prevent the problematic drinking behavior abroad that negatively affects students and institutions, as well as serve as a model to address alcohol risk for other young adults living and traveling abroad. 


\section{Abbreviations}

B-YAACQ: Brief Young Adult Alcohol Consequences Questionnaire; DDQ: Daily Drinking Questionnaire; DNRF: Drinking Norms Rating Form; PNF: personalized normative feedback; RCT: randomized controlled trial; SAM: Sojourner Adjustment Measure; SAF: sojourner adjustment feedback; SES: Sexual Experiences Survey; SPIRIT: Standard Protocol Items: Recommendations for Interventional Trials; SRS: Sexual Risk Survey.

\section{Acknowledgements}

The authors wish to thank the $3 \mathrm{C}$ Institute for online survey hosting and intervention development, Andrew Langdon for filming and editing intervention content, Michael Woodward and Sarika Bharil for assistance with intervention design and data collection, the study abroad office directors at the universities and colleges from where we recruited, and the students who provided the content for the filmed intervention content.

\section{Authors' contributions}

ERP, EJD, JWL, CF, and BAG conceptualized the study and obtained funding. ERP has overall responsibility for the execution of the intervention, data collection, analyses, and reporting. EJD, JWL, CF, BAG, and DJK will assist ERP with the design and evaluation of the intervention and assist with quantitative data analyses. ERP drafted an initial version of this paper and all other authors provided edits and contributed to all sections. All authors read and approved the final manuscript.

\section{Funding}

This work was funded by a grant from the National Institute on Alcohol Abuse and Alcoholism (R01AA025909, "Online Intervention to Prevent Risky Behaviors During College Student Study Abroad Experiences") awarded to Eric R. Pedersen.

\section{Availability of data and materials}

Once collected, deidentified data from this study will be available by request to the corresponding author 1 year after all aims of the project are completed. Requestors of data will be asked to complete a data-sharing agreement that provides for (1) a commitment to using the data only for research purposes and not to identify any individual participant; (2) a commitment to securing the data using appropriate computer technology and (3) a commitment to destroying or returning the data after analyses are completed.

\section{Ethics approval and consent to participate}

This study, including all procedures and consent materials, was approved by the RAND Human Subjects Protection Committee.

\section{Consent for publication}

Not applicable.

\section{Competing interests}

The authors declare that they have no competing interests.

\section{Author details}

${ }^{1}$ RAND Corporation, 1776 Main Street, PO Box 2138, Santa Monica, CA 90407-2138, USA. ${ }^{2}$ Department of Psychology, Loyola Marymount University, 1 LMU Drive, Los Angeles, CA 90045, USA. ${ }^{3}$ RAND Corporation, 4570 Fifth Ave, Ste. \#600, Pittsburgh, PA 15213, USA. ${ }^{4}$ RAND Corporation, 1200 South Hayes Street, Arlington, VA 22202, USA.

\section{Appendix}

Modified sexual experiences survey reflecting study abroad context and incorporating items from the National Drugfacilitated, Incapacitated, and Forcible Rape Study

\begin{tabular}{|c|c|c|c|}
\hline Domain & Female item wording & Male item wording & Gender-neutral item wording \\
\hline Introduction & $\begin{array}{l}\text { Intro to items: Many women have expe- } \\
\text { rienced unwanted sexual advances at } \\
\text { some point during their lives. Women } \\
\text { do not always report such experiences } \\
\text { to police or discuss them with family } \\
\text { or friends. Such experiences can hap- } \\
\text { pen anytime in a woman's life-even } \\
\text { as a child. The person making these } \\
\text { unwanted advances can be friends, } \\
\text { boyfriends, girlfriends, coworkers, } \\
\text { teaching assistants, supervisors, family } \\
\text { members, strangers, or someone } \\
\text { they just met. The person making the } \\
\text { unwanted sexual advances can be } \\
\text { male or female }\end{array}$ & $\begin{array}{l}\text { Intro to items: Many men have experienced } \\
\text { unwanted sexual advances at some point } \\
\text { during their lives. Men do not always report } \\
\text { such experiences to police or discuss them with } \\
\text { family or friends. Such experiences can happen } \\
\text { anytime in man's life-even as a child. The } \\
\text { person making these unwanted advances can } \\
\text { be friends, girlfriends, boyfriends, coworkers, } \\
\text { teaching assistants, supervisors, family mem- } \\
\text { bers, strangers, or someone they just met. The } \\
\text { person making the unwanted sexual advances } \\
\text { can be male or female }\end{array}$ & $\begin{array}{l}\text { Many people have experienced unwanted } \\
\text { sexual advances at some point during their } \\
\text { lives. Men and women do not always report } \\
\text { such experiences to police or discuss them } \\
\text { with family or friends. Such experiences can } \\
\text { happen anytime in a person's life-even as } \\
\text { a child. The person making these unwanted } \\
\text { advances can be friends, boyfriends, } \\
\text { girlfriends, coworkers, teaching assistants, } \\
\text { supervisors, family members, strangers, or } \\
\text { someone they just met. The person making } \\
\text { the unwanted sexual advances can be male } \\
\text { or female }\end{array}$ \\
\hline $\begin{array}{l}\text { Nonconsensual/ } \\
\text { unwanted } \\
\text { sexual contact } \\
\text { (1 item) }\end{array}$ & $\begin{array}{l}\text { 1. Has anyone ever fondled, kissed, or } \\
\text { rubbed up against the private areas of } \\
\text { your body (lips, breast/chest, crotch } \\
\text { or butt) or removed some of your } \\
\text { clothes without your consent (but did } \\
\text { not attempt sexual penetration)? }\end{array}$ & $\begin{array}{l}\text { 1. Has anyone ever fondled, kissed, or rubbed } \\
\text { up against the private areas of your body (lips, } \\
\text { chest, crotch or butt) or removed some of } \\
\text { your clothes without your consent (but did not } \\
\text { attempt sexual penetration)? }\end{array}$ & $\begin{array}{l}\text { 1. Has anyone ever fondled, kissed, or rubbed } \\
\text { up against the private areas of your body } \\
\text { (lips, breast/chest, crotch or butt) or removed } \\
\text { some of your clothes without your consent } \\
\text { (but did not attempt sexual penetration)? }\end{array}$ \\
\hline
\end{tabular}




\begin{tabular}{|c|c|}
\hline Domain & Female item wording \\
\hline $\begin{array}{l}\text { Sexual coercion } \\
\text { ( } 2 \text { items) }\end{array}$ & $\begin{array}{l}\text { 2. Has anyone ever had sex with you } \\
\text { without your consent by telling lies, } \\
\text { threatening to end the relationship, } \\
\text { threatening to spread rumors about } \\
\text { you, making promises you knew were } \\
\text { untrue, or continually verbally pressur- } \\
\text { ing you after you said you didn't want } \\
\text { to. By having sex, we mean that a man } \\
\text { or boy put his penis in your vagina, } \\
\text { your anus, or your mouth } \\
\text { 3. Has anyone ever had sex with you } \\
\text { without your consent by showing } \\
\text { displeasure, criticizing your sexuality } \\
\text { or attractiveness, getting angry but } \\
\text { not using physical force, after you said } \\
\text { you didn't want to. By having sex, we } \\
\text { mean that a man or boy put his penis } \\
\text { in your vagina, your anus, or your } \\
\text { mouth }\end{array}$ \\
\hline
\end{tabular}

Male item wording

2. Has anyone ever had sex with you without your consent by telling lies, threatening to end the relationship, threatening to spread rumors about you, making promises you knew were untrue, or continually verbally pressuring you after you said you didn't want to. By having sex, we mean that a man or boy put his penis in your anus or your mouth, someone made you put your penis in their vagina or anus, or someone made you put your mouth on their vagina or anus

3. Has anyone ever had sex with you without your consent by showing displeasure, criticizing your sexuality or attractiveness, getting angry but not using physical force, after you said you didn't want to. By having sex, we mean that a man or boy put his penis in your anus or your mouth, someone made you put your penis in their vagina or anus, or someone made you put your mouth on their vagina or anus
Gender-neutral item wording

2. Has anyone ever had sex with you without your consent by telling lies, threatening to end the relationship, threatening to spread rumors about you, making promises you knew were untrue, or continually verbally pressuring you after you said you didn't want to. By having sex, we mean that a man or boy put his penis in your vagina, your anus, or your mouth; someone made you put your penis in their vagina, anus, or mouth; or someone made you put your mouth on their vagina or anus

3. Has anyone ever had sex with you without your consent by showing displeasure, criticizing your sexuality or attractiveness, getting angry but not using physical force, after you said you didn't want to. By having sex, we mean that a man or boy put his penis in your vagina, your anus or your mouth; someone made you put your penis in their vagina, anus, or mouth, or someone made you put your mouth on their vagina or anus

4. Has anyone, male or female, ever made you have vaginal sex by using force or threatening to harm you or someone close to you? Just so there is no mistake, by vaginal sex, we mean putting a penis in a vagina

5. Has anyone, male or female, ever made you have oral sex by force or threatening to harm you? So there is no mistake, by oral sex, we mean that a man or boy put his penis in your mouth, someone made you put your mouth or tongue in their vagina or anus, or someone penetrated your vagina or anus with their mouth or tongue

6. Has anyone ever made you have anal sex by force or threatening to harm you? By anal sex we mean putting their penis in your anus or rectum or making you put your penis in their anus or rectum

7. Has anyone ever put fingers or objects in your vagina or anus against your will by using force or threatening to harm you?
Alcohol- and drug-facilitated sexual assaults (2 items)
6. Has anyone ever made you have ana sex by force or threatening to harm you? By anal sex, we mean putting their penis in your anus or rectum

7. Has anyone ever put fingers or objects in your vagina or anus against your will by using force or threatening to harm you?

Intro to section. Some women have had sex when they didn't want to because they were very high, intoxicated, or even passed out because of alcohol or drugs. We would like to ask you about these types of experiences you might have had. Again, we are interested in these experiences regardless of how long ago it happened, who did it, or whether or not it was reported to police

8. Has anyone ever had sex with you when you didn't want to after you drank so much alcohol that you were very high, drunk, or passed out? By having sex, we mean that a man or boy put his penis in your vagina, your anus, or your mouth

9. Has anyone ever had sex with you when you didn't want to after they gave you, or you had taken enough drugs to make you very high, intoxicated, or passed out? By having sex, we mean that a man or boy put his penis in your vagina, your anus, or your mouth
. Has anyone ever made you have anal sex force or threatening to harm you? By anal sex we mean putting their penis in your anus or

7. Has anyone ever put fingers or objects in you anus against your will by using force or threatening to harm you?

Intro to section: Some men have had sex when they didn't want to because they were very high, intoxicated, or even passed out because of alcohol or drugs. We would like to ask you about these types of experiences you might have had. Again, we are interested in these experiences regardless of how long ago it happened, who did it, or whether or not it was reported to police

8. Has anyone ever had sex with you when you didn't want to after you drank so much alcoho that you were very high, drunk, or passed out? By having sex, we mean that a man or boy put his penis in your anus or your mouth, someone made you put your penis in their vagina or anus, or someone made you put your mouth on their vagina or anus

9. Has anyone ever had sex with you when you didn't want to after they gave you, or you had taken enough drugs to make you very high, intoxicated, or passed out? By having sex, we mean that a man or boy put his penis in your anus or your mouth, someone made you put your penis in their vagina or anus, or someone made you put your mouth on their vagina or anus
Intro to section: Some people have had sex when they didn't want to because they were very high, intoxicated, or even passed out because of alcohol or drugs. We would like to ask you about these types of experiences you might have had. Again, we are interested in these experiences regardless of how long ago it happened, who did it, or whether or not it was reported to police

8. Has anyone ever had sex with you when you didn't want to after you drank so much alcohol that you were very high, drunk, or passed out? By having sex, we mean that a man or boy put his penis in your vagina, your anus, or your mouth; someone made you put your penis in their vagina or anus, or someone made you put your mouth on their vagina or anus

9. Has anyone ever had sex with you when you didn't want to after they gave you, or you had taken enough drugs to make you very high, intoxicated, or passed out? By having sex, we mean that a man or boy put his penis in your vagina, your anus, or your mouth; someone made you put your penis in their vagina or anus, or someone made you put your mouth on their vagina or anus 


\begin{tabular}{|c|c|c|c|}
\hline Domain & Female item wording & Male item wording & Gender-neutral item wording \\
\hline $\begin{array}{l}\text { Attempted sex- } \\
\text { ual assaults ( } 3 \\
\text { items) }\end{array}$ & $\begin{array}{l}\text { 10. Has anyone ever attempted to have } \\
\text { vaginal, oral, or anal sex with you } \\
\text { when you did not want to or put } \\
\text { fingers or objects in your vagina or } \\
\text { anus against your will but was not } \\
\text { successful? } \\
\text { 11. When you had been very high, drunk, } \\
\text { or passed out from alcohol, has anyone } \\
\text { ever attempted to have vaginal, oral, } \\
\text { or anal sex with you or tried to put } \\
\text { fingers or objects in your vagina or } \\
\text { anus against your will but was not } \\
\text { successful? } \\
\text { 12. When you had been very high, } \\
\text { intoxicated, or passed out from drugs, } \\
\text { has anyone ever attempted to have } \\
\text { vaginal, oral, or anal sex with you or } \\
\text { tried to put fingers or objects in your } \\
\text { vagina or anus against your will but } \\
\text { was not successful? }\end{array}$ & $\begin{array}{l}\text { 10. Has anyone ever attempted to have oral, vagi- } \\
\text { nal, or anal sex with you when you did not want } \\
\text { to or put fingers or objects in your anus against } \\
\text { your will but was not successful? } \\
\text { 11. When you had been very high, drunk, or passed } \\
\text { out from alcohol, has anyone ever attempted to } \\
\text { have oral, vaginal, or anal sex with you or tried } \\
\text { to put fingers or objects in your anus against } \\
\text { your will but was not successful? } \\
\text { 12. When you had been very high, intoxicated, } \\
\text { or passed out from drugs, has anyone ever } \\
\text { attempted to have oral, vaginal, or anal sex with } \\
\text { you or tried to put fingers or objects in your } \\
\text { anus against your will but was not successful? }\end{array}$ & $\begin{array}{l}\text { 10. Has anyone ever attempted to have vaginal, } \\
\text { oral, or anal sex with you when you did not } \\
\text { want to or put fingers or objects in your } \\
\text { vagina or anus against your will but was not } \\
\text { successful? } \\
\text { 11. When you had been very high, drunk, or } \\
\text { passed out from alcohol, has anyone ever } \\
\text { attempted to have vaginal, oral, or anal sex } \\
\text { with you or tried to put fingers or objects in } \\
\text { your vagina or anus against your will but was } \\
\text { not successful? } \\
\text { 12. When you had been very high, intoxicated, } \\
\text { or passed out from drugs, has anyone ever } \\
\text { attempted to have vaginal, oral, or anal sex } \\
\text { with you or tried to put fingers or objects in } \\
\text { your vagina or anus against your will but was } \\
\text { not successful? }\end{array}$ \\
\hline
\end{tabular}

Female items displayed to participants indicating female sex and female gender. Male items displayed to participants indicating male sex and male gender. Gender-neutral items displayed to participants who choose not to indicate a sex, chose a gender that is different than their sex, who describe their gender as transgender, or who do not identify as male, female, or transgender.

Response options at predeparture: Regardless of how long ago it happened or who made the unwanted sexual advances...

$0=$ No, this has never happened to me

$1=$ Yes, this happened to me before I started college

$2=$ Yes, this happened to me during college

$3=$ Yes, this happened to me before college and during college

Response options at last month abroad: Consider your entire trip abroad. Regardless of when it happened during your trip or who made the unwanted sexual advances...

$$
\begin{aligned}
& 0=\mathrm{No} \\
& 1=\mathrm{Yes}
\end{aligned}
$$

Also, on the last month abroad survey, all items will be prefaced with "During your study abroad trip..."

Response options at 3-month post-return: Consider the past 3 months (i.e., the time since you have been back in the US since your study abroad trip ended). Regardless of when during this time it happened or who made the unwanted sexual advances...

$0=$ No, this has not happened to me

$1=$ Yes, this happened to me since I have returned from study abroad

Also, on the 3-month post-return survey, all items will be prefaced with "During the past 3 months since you have been home from your study abroad trip..." 


\section{SD D}

Standard Protocol Items: Recommendations for Interventional Trials

SPIRIT 2013 Checklist: Recommended items to address in a clinical trial protocol and related documents

$\begin{array}{lll}\text { Section/item } & \text { Item Description } & \text { Addressed on } \\ & \text { No } & \text { page number }\end{array}$

\section{Administrative information}

Title

Trial registration

$2 a$
trial acronym

2b All items from the World Health Organization Trial Registration Data Set

Protocol version 3

Funding

Roles and responsibilities

4

Date and version identifier

$5 a$

5a Names, affiliations, and roles of protocol contributors

5b Name and contact information for the trial sponsor

5c Role of study sponsor and funders, if any, in study design; collection, management, analysis, and interpretation of data; writing of the report; and the decision to submit the report for publication, including whether they will have ultimate authority over any of these activities

5d Composition, roles, and responsibilities of the coordinating centre, steering committee, endpoint adjudication committee, data management team, and other individuals or groups overseeing the trial, if applicable (see Item 21a for data monitoring committee)

\section{Introduction}

Background and $6 a$ rationale

6b Explanation for choice of comparators

Objectives

7

Trial design
Sources and types of financial, material, and other support
Description of research question and justification for undertaking the trial, including summary of relevant studies (published and unpublished) examining benefits and harms for each intervention

Specific objectives or hypotheses

Description of trial design including type of trial (eg, parallel group, crossover, factorial, single group), allocation ratio, and framework (eg, superiority, equivalence, noninferiority, exploratory)

\section{page number}

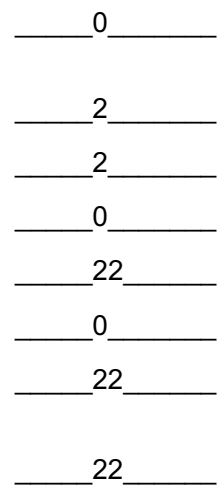

22

$3-10$

11

9-10

10

11

Description of study settings (eg, community clinic, academic hospital) and list of countries where data will be collected. Reference to where list of study sites can be obtained

Eligibility criteria 10 Inclusion and exclusion criteria for participants. If applicable, eligibility criteria for study centres and individuals who will perform the interventions (eg, surgeons, psychotherapists)

Interventions

11a Interventions for each group with sufficient detail to allow replication, including how and when they will be administered

11b Criteria for discontinuing or modifying allocated interventions for a given trial participant (eg, drug dose change in response to harms, participant request, or improving/worsening disease)

11c Strategies to improve adherence to intervention protocols, and any procedures for monitoring adherence (eg, drug tablet return, laboratory tests)

11d Relevant concomitant care and interventions that are permitted or prohibited during the trial
11

$12-14$

$\mathrm{n} / \mathrm{a}$

12

11 
Outcomes 12 Primary, secondary, and other outcomes, including the specific measurement variable (eg, systolic blood pressure), analysis metric (eg, change from baseline, final value, time to event), method of aggregation (eg, median, proportion), and time point for each outcome. Explanation of the clinical relevance of chosen efficacy and harm outcomes is strongly recommended

Participant timeline

Sample size

Recruitment schedule of enrolment, interventions (including any run-ins and washouts), assessments, and visits for participants. A schematic diagram is highly recommended (see Figure)

14 Estimated number of participants needed to achieve study objectives and how it was determined, including clinical and statistical assumptions supporting any sample size calculations

15 Strategies for achieving adequate participant enrolment to reach target sample size

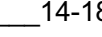

12

\section{Methods: Assignment of interventions (for controlled trials)}

Allocation:

Sequence generation

Allocation concealment mechanism

\section{Blinding}

(masking) 16a Method of generating the allocation sequence (eg, computer-generated random numbers), 13 and list of any factors for stratification. To reduce predictability of a random sequence, details of any planned restriction (eg, blocking) should be provided in a separate document that is unavailable to those who enrol participants or assign interventions

$16 \mathrm{~b}$ Mechanism of implementing the allocation sequence (eg, central telephone; sequentially numbered, opaque, sealed envelopes), describing any steps to conceal the sequence until interventions are assigned

16c Who will generate the allocation sequence, who will enrol participants, and who will assign participants to interventions

17a Who will be blinded after assignment to interventions (eg, trial participants, care providers, outcome assessors, data analysts), and how

17b If blinded, circumstances under which unblinding is permissible, and procedure for revealing a participant's allocated intervention during the trial

13

13 $\mathrm{n} / \mathrm{a}$

$\mathrm{n} / \mathrm{a}$
$14-18$ any related processes to promote data quality (eg, duplicate measurements, training of assessors) and a description of study instruments (eg, questionnaires, laboratory tests) along with their reliability and validity, if known. Reference to where data collection forms can be found, if not in the protocol

18b Plans to promote participant retention and complete follow-up, including list of any outcome data to be collected for participants who discontinue or deviate from intervention protocols

Data

management

Plans for data entry, coding, security, and storage, including any related processes to promote data quality (eg, double data entry; range checks for data values). Reference to where details of data management procedures can be found, if not in the protocol

Statistical methods

Statistical methods for analysing primary and secondary outcomes. Reference to where other details of the statistical analysis plan can be found, if not in the protocol

20b Methods for any additional analyses (eg, subgroup and adjusted analyses)

20c Definition of analysis population relating to protocol non-adherence (eg, as randomised analysis), and any statistical methods to handle missing data (eg, multiple imputation)

\section{Methods: Monitoring}

Data monitoring 21a Composition of data monitoring committee (DMC); summary of its role and reporting structure; statement of whether it is independent from the sponsor and competing interests; and reference to where further details about its charter can be found, if not in the protocol. Alternatively, an explanation of why a DMC is not needed

21b Description of any interim analyses and stopping guidelines, including who will have access to these interim results and make the final decision to terminate the trial

Plans for collecting, assessing, reporting, and managing solicited and spontaneously reported adverse events and other unintended effects of trial interventions or trial conduct

$14-18$

12

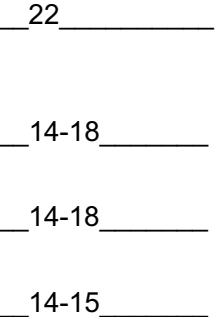

$\mathrm{n} / \mathrm{a}$ $\mathrm{n} / \mathrm{a}$ $\mathrm{n} / \mathrm{a}$ 
Auditing $23 \quad$ Frequency and procedures for auditing trial conduct, if any, and whether the process will $\mathrm{n} / \mathrm{a}$ be independent from investigators and the sponsor

\section{Ethics and dissemination}

Research ethics 24 Plans for seeking research ethics committee/institutional review board (REC/IRB) approval 22 approval

Protocol amendments

Plans for communicating important protocol modifications (eg, changes to eligibility criteria,

22 registries, journals, regulators)

Consent or assent

26a Who will obtain informed consent or assent from potential trial participants or authorised surrogates, and how (see Item 32)

26b Additional consent provisions for collection and use of participant data and biological specimens in ancillary studies, if applicable

Confidentiality 27 How personal information about potential and enrolled participants will be collected, shared, and maintained in order to protect confidentiality before, during, and after the trial

Declaration of

28 Financial and other competing interests for principal investigators for the overall trial and each study site

interests

Access to data 29 Statement of who will have access to the final trial dataset, and disclosure of contractual agreements that limit such access for investigators

30 Provisions, if any, for ancillary and post-trial care, and for compensation to those who suffer harm from trial participation

Ancillary and post-trial care

31a Plans for investigators and sponsor to communicate trial results to participants, healthcare professionals, the public, and other relevant groups (eg, via publication, reporting in results policy databases, or other data sharing arrangements), including any publication restrictions

31b Authorship eligibility guidelines and any intended use of professional writers

31c Plans, if any, for granting public access to the full protocol, participant-level dataset, and statistical code

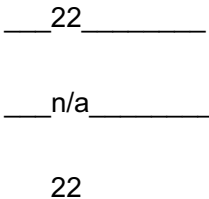

22

\section{Appendices}

Informed consent 32 materials

Model consent form and other related documentation given to participants and authorised surrogates

Biological specimens

Plans for collection, laboratory evaluation, and storage of biological specimens for genetic or molecular analysis in the current trial and for future use in ancillary studies, if applicable $\mathrm{n} / \mathrm{a}$

*It is strongly recommended that this checklist be read in conjunction with the SPIRIT 2013 Explanation \& Elaboration for important clarification on the items. Amendments to the protocol should be tracked and dated. The SPIRIT checklist is copyrighted by the SPIRIT Group under the Creative Commons “Attribution-NonCommercial-NoDerivs 3.0 Unported” license.
Received: 15 May 2019 Accepted: 10 August 2019

Published online: 20 August 2019

\section{References}

1. Institute of International Education. Open doors 2018: report on international educational exchange. New York: Author; 2018

2. Kitsantas A. Studying abroad: the role of college students' goals on the development of cross-cultural skills and global understanding. Coll Stud J. 2004;38:441-53.

3. Kitsantas A, Meyers J. Studying abroad: does it enhance college student cross-cultural awareness? In: Annual Meeting of the San Diego State University and the U.S. Department of Education Centers for International Business Education and Research, San Diego, CA. 2001.

4. Kauffmann NL, Kuh GD. The impact of study abroad on personal development of college students. J Int Stud Personnel. 1984;6-10.

5. Lewin $R$, editor. The handbook of practice and research in study abroad: higher education and the quest for global citizenship. New York: Routledge; 2009.
6. Sutton RC, Rubin DL. Documenting the academic impact of study abroad: final report of the GLOSSARI project. In: NAFSA annual conference; Kansas City, Missouri. 2010.

7. Sutton RC, Rubin DL. The GLOSSARI Project: initial findings from a system-wide research initiative on study abroad learning outcomes. Front Interdiscip J Stud Abroad. 2004;10:65-82.

8. Dwyer MM. More is better: the impact of study abroad program duration. Front Interdiscip J Stud Abroad. 2004:10:151-63.

9. Hummer JF, Pedersen ER, Mirza T, LaBrie JW. Factors associated with general and sexual alcohol-related consequences: an examination of college students studying abroad. J Stud Affairs Res Pract. 2010;47(4):427-44.

10. Pedersen ER, Neighbors C, Lee CM, Larimer ME. Not all those who wander are lost: examining the impact of sojourner adjustment and drinking motives on alcohol consequences experienced by Americans studying in foreign countries. J Stud Alcohol Drugs. 2012;73(6):1005-15.

11. Pedersen ER, Larimer ME, Lee CM. When in Rome: factors associated with changes in drinking behavior among American college students 
studying abroad. Psychol Addict Behav. 2010;24(3):535-40. https://doi. org/10.1037/a0019863.

12. Epstein J. Last call for US students studying abroad? Continuing concerns about alcohol use and abuse during study abroad. SAFETI On-Line Newsletter. Vol. 3, No.1, 2005. http://globaled.us/safeti/v3n12 005ed_last_call_for_us_students.asp. Accessed 15 Apr 2019.

13. Epstein J, Rhodes G. A discussion about alcohol and student exchange. SAFETI OnLine Newsletter, Vol. 1 2000. http://globaled.us/safeti/v1n22 000ed_alcohol and_student_exchange.asp. Accessed 15 Apr 2019

14. Forum on Education Abroad. State of the field survey: 2008. Carlisle: Dickinson College; 2009.

15. LaBrie JW, Pedersen ER, Hummer JF, Rhodes G. The expansion of international programs highlight the need for effective and validated alcohol harm reduction programs. The Addictions Newsletter. 2013;Fall/ Winter. https://www.addictionpsychology.org/sites/default/files/publi c/pubs/TAN_Fall2013.pdf. Accessed 16 Sept 2018.

16. Koss MP, Gidycz CA. Sexual experiences survey: reliability and validity. J Consult Clin Psychol. 1985;53(3):422-3.

17. Palmer RS, McMahon TJ, Rounsaville BJ, Ball SA. Coercive sexual experiences, protective behavioral strategies, alcohol expectancies and consumption among male and female college students. J Interpers Violence. 2010;25(9):1563-78. https://doi.org/10.1177/0886260509354581.

18. Abbey A. Alcohol's role in sexual violence perpetration: theoretical explanations, existing evidence and future directions. Drug Alcohol Rev. 2011;30(5):481-9.

19. Abbey A, Zawacki T, Buck PO, Clinton AM, McAuslan P. Sexual assault and alcohol consumption: what do we know about their relationship and what types of research are still needed? Aggress Violent Behav. 2004;9(3):271-303.

20. Testa M, Hoffman JH. Naturally occurring changes in women's drinking from high school to college and implications for sexual victimization. J Stud Alcohol Drugs. 2012;73(1):26-33.

21. Tjaden $\mathrm{P}$, Thoennes N. Extent, nature, and consequences of rape victimization: findings from the National Violence Against Women Survey. Washington, D.C.: National Institute of Justice; 2006

22. Neal DJ, Fromme K. Hook'em horns and heavy drinking: alcohol use and collegiate sports. Addict Behav. 2007;32(11):2681-93.

23. Marcantonio T, Angelone D, Schaffer A. Reading, writing and risk. An investigation of the study abroad population. In: Eastern psychological association conference, New York, NY. 2013.

24. Marcantonio T, Angelone DJ. Sexual victimization in the study abroad environment. San Diego: The Society for the Scientific Study of Sexuality; 2013.

25. Kimble M, Flack WF Jr, Burbridge E. Study abroad increases risk for sexual assault in female undergraduates: a preliminary report. Psychol Trauma Theory Res Pract Policy. 2013;5(5):426-30.

26. Flack WF Jr, Kimble MO, Campbell BE, Hopper AB, Peterca O, Heller EJ. Sexual assault victimization among female undergraduates during study abroad: a single campus survey study. J Interpers Violence. 2014.

27. Krebs CP, Lindquist CH, Warner TD, Fisher BS, Martin SL. College women's experiences with physically forced, alcohol- or other drug-enabled, and drug-facilitated sexual assault before and since entering college. J Am Coll Health. 2009:57(6):639-47.

28. Aresi G. Drinking, drug use, and related consequences among university students completing study abroad experiences: a systematic review. Subst Use Misuse. 2016;51(14):1888-904.

29. Marcantonio TL, Swirsky J, Angelone DJ, Joppa M, Jozkowski KN. A content analysis of sexual health and substance use information presented on study abroad websites: findings and recommendations. J Am Coll Health. 2018:67(6):1-9.

30. Marcantonio TL, Angelone D, Swirsky J, Joppa M. An analysis of the sexual health and safety information study abroad directors present their students prior to departure. J Am Coll Health. 2018:1-5.

31. Smucker S, Pedersen ER, LaBrie JW, D'Amico EJ, Farris C, Klein DJ, Griffin BA. There and back again... safely: examining students' reports of substance use and sexual assault prevention program receipt prior to departure abroad. Manuscript submitted for publication. 2019.

32. Pedersen ER, Cruz RA, Labrie JW, Hummer JF. Examining the relationships between acculturation orientations, perceived and actual norms, and drinking behaviors of short-term american sojourners in foreign environments. Prev Sci. 2011:12(4):401-10.
33. Pedersen ER, LaBrie JW, Hummer JF. Perceived behavioral alcohol norms predict drinking for college students while studying abroad. J Stud Alcohol Drugs. 2009;70(6):924-8.

34. Cronce JM, Larimer ME. Individual-focused approaches to the prevention of college student drinking. Alcohol Res Health. 2011:34(2):210-21.

35. Miller MB, Leffingwell T, Claborn K, Meier E, Walters S, Neighbors C. Personalized feedback interventions for college alcohol misuse: an update of Walters \& Neighbors (2005). Psychol Addict Behav. 2012;31:31.

36. White HR. Reduction of alcohol-related harm on United States college campuses: the use of personal normative feedback interventions. Int J Drug Policy. 2006;17:310-9.

37. Miller DT, Prentice DA. Changing norms to change behavior. Annu Rev Psychol. 2016;67(1):339-61.

38. Miller MB, Leffingwell T, Claborn K, Meier E, Walters ST, Neighbors C. Personalized feedback interventions for college alcohol misuse: an update of Walters \& Neighbors (2005). Psychol Addict Behav. 2013;27:909-20.

39. Larimer ME, Lewis MA, Kilmer JR, Atkins AC, Lee CM, et al. Injunctive and descriptive norms feedback for college drinking prevention: is the whole greater than the sum of the parts?. San Francisco: Research Society on Alcoholism; 2012.

40. Lewis MA, Neighbors C, Oster-Aaland L, Kirkeby BS, Larimer ME. Indicated prevention for incoming freshmen: personalized normative feedback and high-risk drinking. Addict Behav. 2007;32(11):2495-508.

41. Neighbors C, Lee CM, Lewis MA, Fossos N, Walter T. Internet-based personalized feedback to reduce 21st-birthday drinking: a randomized controlled trial of an event-specific prevention intervention. J Consult Clin Psychol. 2009;77(1):51-63.

42. Grossbard J, Hummer J, LaBrie J, Pedersen E, Neighbors C. Is substance use a team sport? Attraction to team, perceived norms, and alcohol and marijuana use among male and female intercollegiate athletes. J Appl Sport Psychol. 2009;21(3):247-61.

43. LaBrie JW, Hummer JF, Neighbors C, Pedersen ER. Live interactive group-specific normative feedback reduces misperceptions and drinking in college students: a randomized cluster trial. Psychol Addict Behav. 2008:22(1):141-8.

44. Neighbors C, LaBrie JW, Hummer JF, Lewis MA, Lee CM, Desai S, et al. Group identification as a moderator of the relationship between perceived social norms and alcohol consumption. Psychol Addict Behav. 2010;24(3):522-8.

45. LaBrie JW, Lewis MA, Atkins DC, Neighbors C, Zheng C, Kenney SR, et al. RCT of web-based personalized normative feedback for college drinking prevention: are typical student norms good enough? J Consult Clin Psychol. 2013;12:12

46. Carey KB, Henson JM, Carey MP, Maisto SA. Perceived norms mediate effects of a brief motivational intervention for sanctioned college drinkers. Clin Psychol. 2010;17(1):58-71.

47. Wood MD, Capone C, Laforge R, Erickson DJ, Brand NH. Brief motivational intervention and alcohol expectancy challenge with heavy drinking college students: a randomized factorial study. Addict Behav. 2007:32(11):2509-28.

48. Reid AE, Carey KB. Interventions to reduce college student drinking: state of the evidence for mechanisms of behavior change. Clin Psychol Rev. 2015:40:213-24.

49. Neighbors C, Lee CM, Atkins DC, Lewis MA, Kaysen D, Mittmann A, et al. A randomized controlled trial of event-specific prevention strategies for reducing problematic drinking associated with 21st birthday celebrations. J Consult Clin Psychol. 2012;80(5):850-62.

50. Patrick ME, Lewis MA, Lee CM, Maggs JL. Semester and event-specific motives for alcohol use during Spring Break: associated protective strategies and negative consequences. Addict Behav. 2013;38(4):1980-7.

51. Patrick ME, Lee CM, Neighbors C. Web-based intervention to change perceived norms of college student alcohol use and sexual behavior on spring break. Addict Behav. 2014;39(3):600-6.

52. Pedersen ER, Neighbors C, Atkins DC, Lee CM, Larimer ME. Brief online interventions targeting risk and protective factors for increased and problematic alcohol use among American college students studying abroad. Psychol Addict Behav. 2017;31:220-30.

53. Berry JW. Immigration, acculturation, and adaptation. Appl Psychol. 1997;46(1):5-34.

54. Berry JW. Conceptual approaches to acculturation. In: Chun KM, Organista PB, Marín G, editors. Acculturation: advances in theory, 
measurement and applied research. Washington, D.C.: American Psychological Association; 2003. p. 17-37.

55. Church A. Sojourner adjustment. Psychol Bull. 1982;91:540-72.

56. Ward C, Rana-Deuba A. Acculturation and adaptation revisited. J Cross Cult Psychol. 1999;30(4):422-42.

57. Berry JW. Acculturative stress. In: Organista PB, Chun KM, Marin G, editors. Readings in ethnic psychology. New York: Routledge; 1998. p. 113-7.

58. Searle W, Ward C. The prediction of psychological and sociocultural adjustment during cross-cultural transitions. Int J Intercult Relat. 1990;14(4):449-64.

59. Ward C, Kennedy A. Acculturation strategies, psychological adjustment, and sociocultural competence during cross-cultural transitions. Int Intercult Relat. 1994;18(3):329-43.

60. Ward C, Rana-Deuba A. Home and host culture influences on sojourner adjustment. Int J Intercult Relat. 2000;24(3):291-306.

61. Jankowiak W, White CT. Carnival on the clipboard: an ethnological study of New Orleans Mardi Gras. Ethnology. 1999;38(4):335-49.

62. Maticka-Tyndale E, Herold ES, Mewhinney D. Casual sex on spring break: intentions and behaviors of Canadian students. J Sex Res. 1998:35(3):254-64.

63. Triandis HC. Interpersonal behavior. Monterey: Brooks/Cole; 1977.

64. Milhausen RR, Reece M, Perera B. A theory-based approach to understanding sexual behavior at Mardi Gras. J Sex Res. 2006;43(2):97-106.

65. Mitchell MA, Poyrazli S, Matukaitis Broyles L. Hazardous alcohol use and cultural adjustment among U.S. college students abroad in Italy: findings and recommendations for study abroad staff and researchers. Subst Abus. 2016:37:215-21.

66. Wielkiewicz RM, Turkowski LW. Reentry issues upon returning from study abroad programs. J Coll Stud Dev. 2010;5:649-64.

67. Black JS, Mendenhall M. Cross-cultural training effectiveness: a review and a theoretical framework for future research. Acad Manag Rev. 1990;15(1):113-36.

68. Wilkinson S. On the nature of immersion during study abroad: some participant perspectives. Front Interdiscip J Study Abroad. 1998:4:121-38.

69. Winkelman M. Cultural shock and adaptation. J Counsel Dev. 1994;73(2):121-6.

70. Murphy JG, Correia CJ, Barnett NP. Behavioral economic approaches to reduce college student drinking. Addict Behav. 2007;32(11):2573-85.

71. Bandura A. Social learning theory. Upper Saddle River: Prentice Hall; 1977.

72. Pedersen ER, Skidmore JR, Aresi G. Demographic and predeparture factors associated with drinking and alcohol-related consequences for college students completing study abroad experiences. J Am Coll Health. 2014;62(4):244-54

73. Pedersen ER, LaBrie JW, Hummer JF, Larimer ME, Lee CM. Heavier drinking American college students may self-select into study abroad programs: an examination of sex and ethnic differences within a highrisk group. Addict Behav. 2010;35(9):844-7. https://doi.org/10.1016/j. addbeh.2010.04.003.

74. Gilmore A, Lewis M, George W. A randomized controlled trial targeting alcohol use and sexual assault risk among college women at high risk for victimization. Behav Res Ther. 2015;74:38-49.

75. Senn CY, Eliasziw M, Barata PC, Thurston WE, Newby-Clark IR, Radtke $\mathrm{HL}$, et al. Efficacy of a sexual assault resistance program for university women. N Engl J Med. 2015:372(24):2326-35.

76. Pedersen ER, Parast L, Marshall GN, Schell TL, Neighbors C. A randomized controlled trial for a web-based personalized normative feedback alcohol intervention for young adult veterans. J Consult Clin Psychol. 2017:85:459-70.

77. Pedersen ER, Neighbors C, Larimer ME, Lee CM. Measuring Sojourner Adjustment among American students studying abroad. Int J Intercult Relat. 2011;35(6):881-9.

78. Chan KK, Neighbors C, Gilson M, Larimer ME, Alan Marlatt G. Epidemiological trends in drinking by age and gender: providing normative feedback to adults. Addict Behav. 2007;32(5):967-76.

79. Collins RL, Parks GA, Marlatt GA. Social determinants of alcohol consumption: the effects of social interaction and model status on the self-administration of alcohol. J Consult Clin Psychol. 1985;53:189-2000.
80. Kahler CW, Strong DR, Read JP. Toward efficient and comprehensive measurement of the alcohol problems continuum in college students: the brief young adult alcohol consequences questionnaire. Alcohol Clin Exp Res. 2005;29(7):1180-9.

81. Kahler CW, Hustad J, Barnett NP, Strong DR, Borsari B. Validation of the 30-day version of the Brief Young Adult Alcohol Consequences Questionnaire for use in longitudinal studies. J Stud Alcohol Drugs. 2008;69(4):611-5.

82. Turchik JA, Garske JP. Measurement of sexual risk taking among college students. Arch Sex Behav. 2009;38(6):936-48.

83. Turchik JA, Walsh K, Marcus DK. Confirmatory validation of the factor structure and reliability of the sexual risk survey in a large multiuniversity sample of U.S. students. Int J Sex Health. 2015;27(2):93-105.

84. Koss MP, Oros CJ. Sexual Experiences Survey: a research instrument investigating sexual aggression and victimization. J Consult Clin Psychol. 1982:50(3):455-7.

85. Testa M, VanZile-Tamsen C, Livingston JA, Koss MP. Assessing women's experiences of sexual aggression using the sexual experiences survey: evidence for validity and implications for research. Psychol Women Q. 2004:28(3):256-65.

86. Davis KC, Gilmore AK, Stappenbeck CA, Balsan MJ, George WH, Norris J. How to score the sexual experiences survey? A comparison of nine methods. Psychol Violence. 2014;4(4):445-61.

87. Kilpatrick DG, Resnick HS, Ruggiero KJ, Conoscenti LM, McCauley J. Drug-facilitated, incapacitated, and forcible rape: a national study. Charleston: National Criminal Justice Reference Service; 2007.

88. Kenny DA, Korchmaros JD, Bolger N. Lower level mediation in multilevel models. Psychol Methods. 2003;8(2):115-28.

89. MacKinnon DP, Fairchild AJ, Fritz MS. Mediation analysis. Annu Rev Psychol. 2007;58:593-614.

90. MacKinnon DP, Lockwood CM, Hoffman JM, West SG, Sheets V. A comparison of methods to test mediation and other intervening variable effects. Psychol Methods. 2002;7(1):83-104.

91. Shrout PE, Bolger N. Mediation in experimental and nonexperimental studies: new procedures and recommendations. Psychol Methods. 2002;7(4):422-45.

92. Baer JS, Stacy A, Larimer M. Biases in the perception of drinking norms among college students. J Stud Alcohol. 1991:52(6):580-6.

93. Cooper ML. Reasons for drinking among adolescents: development and validation or a four-dimensional measure of drinking motives. Psychol Assess. 1994;6:117-28.

94. Martens MP, Rocha TL, Martin JL, Serrao HF. Drinking motives and college students: further examination of a four-factor model. J Counsel Psychol. 2008;55:289-95.

95. Neighbors C, Larimer ME, Geisner IM, Knee CR. Feeling controlled and drinking motives among college students: contingent self-esteem as a mediator. Self Identity. 2004;3(3):207-24.

96. Chermack ST, Singer K, Beresford TP. Screening for alcoholism among medical inpatients: how important is corroboration of patient selfreport? Alcohol Clin Exp Res. 1998;22(7):1393-8.

97. Farvolden P, Cunningham J, Selby P. Using e-Health programs to overcome barriers to the effective treatment of mental health and addiction problems. J Technol Hum Serv. 2009;27(1):5-22.

98. McCabe SE, Couper MP, Cranford JA, Boyd CJ. Comparison of web and mail surveys for studying secondary consequences associated with substance use: evidence for minimal mode effects. Addict Behav. 2006;31(1):162-8.

99. Turner CF, Ku L, Rogers SM, Lindberg LD, Pleck JH, Sonenstein FL. Adolescent sexual behavior, drug use, and violence: increased reporting with computer survey technology. Science. 1998;280:867-73.

100. Neighbors C, Jensen M, Tidwell J, Walter T, Fossos N, Lewis MA. Socialnorms interventions for light and nondrinking students. Group Process Intergroup Relat. 2011;14(5):651-69.

\section{Publisher's Note}

Springer Nature remains neutral with regard to jurisdictional claims in published maps and institutional affiliations. 